\title{
European Didactic Traditions in Mathematics: Aspects and Examples from Four Selected Cases
}

\author{
Werner Blum, Michèle Artigue, Maria Alessandra Mariotti, \\ Rudolf Sträßer and Marja Van den Heuvel-Panhuizen
}

\begin{abstract}
In this paper, we report on the presentations and activities from the strand on "European Didactic Traditions" during the Thematic Afternoon at ICME-13. The focal point of the first hour of this afternoon were four key features that were identified as common in all European traditions and the second and third hours were devoted to the presentation of concrete examples from four specific traditions, organised in four parallel sessions.
\end{abstract}

\section{Introduction}

Across Europe, there have been a variety of traditions in mathematics education, both in the practice of learning and teaching at school and in research and development, that have resulted from different cultural, historical, and political backgrounds. Nevertheless, several of these traditions share some common features

\footnotetext{
W. Blum $(\bowtie)$

University of Kassel, Kassel, Germany

e-mail: blum@mathematik.uni-kassel.de

M. Artigue

University Paris Diderot, Paris, France

e-mail: michele.artigue@univ-paris-diderot.fr

M.A. Mariotti

University of Siena, Pisa, Italy

e-mail: mariotti21@unisi.it

R. Sträßer

JLU Giessen, Giessen, Germany

e-mail: rudolf.straesser@uni-giessen.de

M. Van den Heuvel-Panhuizen

Utrecht University, Utrecht, Netherlands

e-mail: m.vandenheuvel-panhuizen@uu.nl

(C) The Author(s) 2017 
beyond historic and cultural differences, one of these being the use of the word didactic to denote the science of teaching and learning (didactiek in Dutch, didactique in French, didáctica in Spanish, didattica in Italian, didaktika in Czech, dydaktyka in Polish or didaktik in Swedish, Danish, and German) rather than education, which is common in Anglo-Saxon traditions. These didactic traditions can be traced back as far as to Comenius' Didactica Magna in the 17th century. They share in particular the following common features: a strong connection with mathematics and mathematicians, the key role of theory, the key role of design activities for learning and teaching environments, and a firm basis in empirical research. Other common features (such as an important role of proofs and proving or of the interplay between mathematics and the real world) can be considered part of those four features.

In the following (in Section "The Four Key Features"), we will elaborate a bit more on those four features. This was the main part of the first hour of the Thematic Afternoon at ICME-13. The features will be made more concrete by referring to four selected cases of European traditions in the didactics of mathematics: the Netherlands, France, Italy, and Germany. We will report (in Section "The Four Cases") briefly on the activities that have taken place in the second and third hour of the Thematic Afternoon in four parallel sessions devoted to these four cases. In these sessions, some distinct and specific characteristics beyond the communalities captured by the four features became clearer for each of the four countries. More details of these country-specific activities can be found on the website of ICME-13.

\section{The Four Key Features}

\section{The Role of Mathematics and Mathematicians}

Here we will highlight the role in the didactics of mathematics that some outstanding mathematicians have played in those four countries by their involvement in educational issues such as designing curricula for school or for teacher education and writing textbooks, and by their fostering of the development of mathematics education as a research field. In this respect, a prominent exemplar is Felix Klein (see Tobies, 1981), who also had a great influence on other mathematicians who had the opportunity of getting to know his work during their visits to Germany as researchers.

An important occasion for international comparison of different experiences in the didactics of mathematics was the Fourth International Congress of Mathematicians, which took place in Rome from 6 to 11 April 1908. During this congress, the International Commission on the Teaching of Mathematics (Commission Internationale de l'Enseignement Mathématique, Internationale Mathematische Unterrichtskommission, Commissione Internazionale dell'Insegnamento Matematico) was 
founded (details of the history of this institution can be retrieved at http://www. icmihistory.unito.it/timeline.php).

After a dramatic interruption due to the Second World War, mathematicians were again involved in instances of reforming. In many countries, the ideas and principles of the so-called New Math were shared. We can recognise a common interest in reforming curricula, which may be related to the impact of a new generation of mathematicians on the reorganisation of mathematics initiated by the Bourbaki Group. Thus, although the concrete results of the New Math movement were very different in various countries, a common feature was that substantial innovation entered into school practice through the active involvement of eminent figures such as Gustave Choquet and Jean Dieudonné in France, Emma Castelnuovo in Italy, and Hans Freudenthal in the Netherlands. Castelnuovo is an interesting exemplar of actions coming from inside the school, showing how the particular structure of the Italian school system could allow innovation coming from teachers.

In the context of this reform, new perspectives developed that moved the focus of reflection from issues concerning mathematical content and its organisation in an appropriate curriculum to issues concerning the description and explanation of the learning and teaching of mathematics, giving birth to a new scientific discipline, the didactics of mathematics, that rapidly developed through active international interaction. In some cases, for instance in France and Italy, it is possible to recognise again the strong influence of the mathematicians community, since the first generation of researchers in the didactics of mathematics consisted for the most part of academics affiliated with mathematics departments. This observation does not ignore the existence of a recurrent tension between mathematicians and researchers in mathematics education.

In summary, some common features that can be considered the core of the European tradition of didactics of mathematics can be directly related also to the uninterrupted and fruitful commitment of mathematicians to educational issues and in their intent to improve the teaching and learning of mathematics. An example is the strong role that proofs and proving have in all European traditions.

\section{The Role of Theory}

The word theory in mathematics education denotes a diversity of objects, from very local constructs to structured systems of concepts; some are "home-grown" while others are "borrowed" with some adaptation from other fields, and some have developed over decades while others have emerged only recently. This diversity can also be observed in the four European traditions under consideration.

The French tradition is certainly the most theoretical of these. It has three main pillars: Vergnaud's theory of conceptual fields (see Vergnaud, 1991), Brousseau's theory of didactical situations (TDS) (see Brousseau, 1997), and the anthropological theory of the didactic (ATD) that emerged from Chevallard's theory of didactic 
transposition (see Chevallard \& Sensevy, 2014). These developed over decades with the conviction that mathematics education should be a scientific field of research with fundamental and applied dimensions supported by genuine theoretical constructions and appropriate methodologies giving an essential role to the observation and analysis of didactic systems and to didactical engineering. These theories were first conceived as tools for the understanding of mathematics teaching and learning practices and processes, taking into consideration the diversity of conditions and constraints that shape them, and for identifying associated phenomena, such as the "didactic contract." The three theories are also characterised by a strong epistemological sensitivity. Over the years, this theoretical landscape has been continuously enriched by new constructions and approaches, but efforts have always been made to maintain its global coherence.

The Dutch tradition is less diversified as it has developed around a single approach known today as Realistic Mathematics Education (see Van den Heuvel-Panhuizen \& Drijvers, 2014). It also emerged in the seventies with Freudenthal's intention to give mathematics education a scientific basis. Similar to the French case, this construction was supported by a deep epistemological reflection: Freudenthal's didactical phenomenology of mathematical structures (see Freudenthal, 1983). In this tradition, theoretical development and design are highly interdependent. This is visible in the RME structure, which is made of six principles clearly connected to design: the activity, reality, level, intertwinement, interactivity, and guidance principles. Through design research in line with these principles, many local instruction theories focusing on specific mathematical topics have been produced. RME is still in conceptual development, benefiting from interactions with other approaches such as socio-constructivism, instrumentation theory, and embodied cognition theory.

In the Italian tradition, conversely, it is not possible to identify theories that would have similarly emerged and developed, despite a long-term tradition of action research, collaboratively carried out by mathematicians interested in education and by teachers. Progressively, however, a specific research trend has emerged from this action research and consolidated within a paradigm of research for innovation, leading to the development of specific theoretical frames and constructs (see Arzarello \& Bartolini Bussi, 1998). Boero's construct of field of experience, Bartolini Bussi and Mariotti's theory of semiotic mediation, and Arzarello's constructs of semiotic bundle and action, production, and communication (APC) space represent this trend well.

In Germany, scholars since the early seventies have aimed to create the field of mathematics education as a scientific discipline, as shown by articles published in ZDM in 1974 and also the efforts made by Hans-Georg Steiner to establish an international debate on the theory of mathematics education and the underlying philosophies and epistemologies of mathematics within an international TME group he founded in 1984. However, it would be difficult to identify a specific German way of approaching theoretical issues in mathematics education even though, when seen from the outside, the interactionist approach initiated by Heinrich Bauersfeld seems to have been influential at an international level. Research in Germany 
currently uses a large variety of "local" theories and of corresponding research methods and of corresponding research methods; more information on these theories and methods can be found in Chapter "German-Speaking Traditions in Mathematics Education Research" in this volume.

Thus, the theoretical landscape offered by these four traditions is diverse and heterogeneous. Considering that such diversity is inherent to this field of research, the European community of research in mathematics education has developed specific efforts to build connections, an enterprise today known as "networking between theories." Not surprisingly, researchers from these four traditions are particularly active in that area.

\section{The Role of Design Activities for Teaching and Learning Environments}

Design activities in mathematics education can involve the design of tasks, lessons, teaching sequences, textbooks, curricula, assessments, and ICT-based material or programs for teacher education and can be done by teachers, educators, textbook authors, curriculum and assessment developers, ICT designers, or researchers. Such activities can be ad hoc or research based. Without design, no education is possible. It is through designed instructional materials and processes, in which the intended what and how of teaching is operationalised, that learning environments for students can be created. As such, educational design forms a meeting point of theory and practice through which they influence each other reciprocally. All four European didactic traditions reflect this.

In France, the design of mathematical tasks, situations, or sequences of situations is essential to didactic research and is controlled by the theoretical frameworks underlying this research (see Section "The Role of Theory"). This is clearly reflected in the methodology of didactical engineering within the theory of didactical situations that emerged in the early eighties. Designs are grounded in epistemological analyses, and situations are sought that capture the epistemological essence of the mathematics to be learned. In the last decade, the anthropological theory of the didactic has developed its own design perspective that gives particular importance to identifying issues that question the world and have strong mathematical potential. Design as a development activity mostly takes place within the IREMs. Dissemination happens through the publications of these institutes, professional journals, curricular resources, and some textbooks. Up to now, only a few research projects were aimed at upscaling.

Within the German didactic tradition, two periods can be distinguished. Before the seventies and eighties, design activities were mostly meant for developing learning and teaching environments for direct use in mathematics education. These design activities belonged to the long German tradition of Stoffdidaktik, which focused strongly on mathematical content and course development, with less 
attention on course evaluation. In the seventies, an empirical turn occurred, resulting in design activities done to study the effect of specified didactical variables through classroom experiments. Course development became less prominent, but this was - in one strand of German didactics of mathematics - counterbalanced by defining didactics of mathematics as a "design science" with a strong focus on mathematics. Currently, both approaches to design activities can be found in Germany and have evolved into a topic-specific didactical design research connecting design and empirical research.

In Italy, the role of design has also changed over time. Characteristic for the period from the mid sixties to the mid-eighties were a deep epistemological concern and a strong pragmatic interest in improving classroom mathematics teaching. The theoretical reflection on didactical suggestions and their effectiveness was not so strong. The focus was on the content and its well-crafted presentation in practice, based on conceptual analyses. The period from the mid eighties to the present can be characterised by long and complex processes targeting the development of theoretical constructs based on teaching experiments, with the design of teaching and learning environments simultaneously both as an objective and as a means of the experimentation.

In the Netherlands, a strong tradition in design can be found. Making things work, looking for pragmatic solutions, creativity, and innovation are typical features of the Dutch culture. This emphasis on design can also be found in mathematics education. At the end of the sixties, the reform of mathematics education started with designing an alternative for the mechanistic mathematics education that then prevailed. Initial design activities were practice-oriented. The theory development that resulted in Realistic Mathematics Education (see Section "The Role of Theory") grew from this practical work and later guided further design activities. Design implementation, including contexts, didactical models, longitudinal teaching-learning trajectories, textbook series, examination programs, mathematics events, and digital tool and environments, has been realised through a strong infrastructure of conferences, journals, and networks.

\section{The Role of Empirical Research}

As discussed in Section "The Role of Design Activities for Teaching and Learning Environments", designing learning environments for mathematics has been an important activity in all four countries. This created the need to legitimise such environments. One way to do this has been to show the effectiveness of these environments by means of empirical research (whatever "effectiveness" may mean). Thus, with various institutional settings and with varying visibility, empirical research has an important role in the didactics of mathematics for all four cases. Because of the complexity of the field, direct cause-effect research (mimicking classical natural science research) was soon found difficult, if not impossible. Nevertheless, partly as a fall-out from the need to design learning environments, 
empirical research in European didactics of mathematics developed a variety of questions, aims, topics, and research methods such as statistical analysis with the help of tests and questionnaires, content analysis of curricula and textbooks, and classroom analysis with the help of videos and observation sheets that was sometimes followed by transcript analysis (often with concepts from linguistics). More recently, triangulation and mixed methods complemented the range of research methods used in empirical research in the four countries.

A major division in the plethora of empirical research in the four cases is the difference between large-scale research and small and medium-sized case studies. The COACTIV study in Germany is a prototype of large-scale research. It was designed to investigate teacher competence as a key determinant of instructional quality in mathematics (for more details on COACTIV, see Kunter et al., 2013). A contrasting example is Mithalal's case study on 3D-geometry. Using Duval's déconstruction dimensionelle and the theory of didactical situations as the theoretical framework (see Section "The Role of Theory"), the study took a qualitative approach to analyze the students dealing with the reconstruction of a drawing showing a 3D-configuration (for details see https://hal.archives-ouvertes.fr/tel00590941).

Large-scale research can be further distinguished from medium- or small-scale research along the following lines: Large-scale studies tend to make differences within a representative sample an argument, while small- or medium-scale studies tend to make specialities of the "case" an argument. In addition to this, empirical research can be distinguished along methodological lines: Quantitative studies tend to use (sophisticated) statistical techniques to arrive at general "laws," while qualitative studies tend to use techniques from content analysis to better understand the phenomena.

If we look into purposes of empirical research, we find commonalities and differences in the four European cases. Prescriptive studies, which tend to show how things should be, are found in all four countries, as are descriptive studies, which tend to give the best possible description and understanding of the domain under study while not being primarily interested in changing the domain. We find experimental studies on theories on the didactics of mathematics, which are undertaken to develop or elaborate a theory and put it to a test, in Italy, France, and the Netherlands (less frequently in Germany), while illustrations of an existing theory (as a sort of "existence proof") can be found in all four countries.

Another distinction is action research as opposed to fundamental research. Action research is deeply involved with the phenomena and persons under study and has the main aim of improving the actual teaching and learning; this is widespread in Italy and the Netherlands. In contrast to this, fundamental research tends to prioritise understanding of the phenomena under study and has the major aim of improving theoretical concepts; this type of research can be found in all four European countries. An additional purpose of empirical research can be specific political interests (in contrast to the development of science or in addition to an interest in scientific progress and curriculum development); this type of research can be found especially in Germany. 


\section{The Four Cases}

\section{The Case of France}

The two hours devoted to the French tradition made it possible to enter more deeply into its history, to present some of its achievements, and to reflect on its interactions with other educational cultures. The historical introduction presented by Michèle Artigue and Luc Trouche situated the context of emergence of this tradition and came back to its three pillars (see Section "The Role of Theory") using excerpts from the interviews with Brousseau, Chevallard, and Vergnaud that had been realised for this occasion. It also showed its current dynamism and the productive connections this tradition has established with connected fields such as cognitive ergonomy, leading to original constructions such as the double approach (ergonomic and didactic) of teachers' practices or the instrumental approach. Two case studies prepared by Aurélie Chesnais and Viviane Durand-Guerrier on axial symmetry and by Marianna Bosch and Hamid Chaachoua on algebra were then used to show the progressive development and capitalisation of research within this tradition and how its vision of the field, epistemological sensitivity, and theoretical constructions have led to original perspectives and results. While describing the evolution of research problematics and approaches on these themes over decades, the presenters made clear the attention paid by the French research community to the progressive structuration and capitalisation of didactic knowledge.

The second hour, devoted to influences and interactions, started with an animation prepared by Patrick Gibel showing how the supervision or co-supervision of foreign PhD students has contributed to the dissemination of the French tradition since the seventies. The session was then led by four researchers: Christine Knipping (Germany), Michela Maschietto (Italy), Faïza Chellougui (Tunisia), and Avenilde Romo Vazquez (Mexico), who all have prepared their $\mathrm{PhD}$ in co-supervision with a French researcher. Christine Knipping, who acted as a critical friend, looked at the French tradition through the lenses of validation and proof. Her main points were cohesion, interchanges (both within the French community and beyond), and dissemination, examining the specific role played by $\mathrm{PhD}$ students. Michela Maschietto described her personal journey from fellowship and doctorate in Paris back to Italy and the starting of new and very productive collaborations, combining French and Italian approaches towards material and digital tools. Faïza Chellougui showed the importance of collaboration with French didacticians in the development of didactic research in her country and more globally in francophone Africa, emphasising the specific role played by the EMF structure. Avenilde Romo Vazquez reviewed the long-term history of interaction between France and Latin America, and more specifically France and Mexico, in mathematics education. The four researchers made clear the influence of the French tradition and the collaborative work with French researchers on their personal development, but they also showed how, in return, the French tradition benefits from these international connections, which open it to new questions and constructions. The three interviews 
mentioned above and a document analyzing the history of didactic interactions with eight countries from francophone Africa, Latin America, and Asia, prepared for this thematic afternoon, are accessible on the website of the CFEM, the French sub-commission of ICMI (http://www.cfem.asso.fr/cfem/ICME-13-didactiquefrancaise).

\section{The Case of Italy}

Starting from a short historic overview, a variety of voices illustrated specific aspects of the Italian trend in didattica della matematica, from both inside and outside the community of Italian didacticians. The historic overview highlighted the continuous and increasing interest and involvement of the community of mathematicians in educational issues, in particular the role played by special figures in the emergence and the development of mathematics education as a scientific and autonomous discipline: from Federigo Enriquez to Emma Castelnuovo and from Bruno de Finetti to Giovanni Prodi.

As far as the inner voices are concerned, the contributions of Paolo Boero and of Mariolina Bartolini Bussi highlighted crucial features that shaped Italian didactics and, more specifically, the emergence of studies on mathematics learning and teaching. Some of these features have been related to local conditions, for instance, the high degree of freedom left to the teacher in the design and the realisation of didactic interventions in the Italian school system. Such a freedom has allowed active innovations realised by individuals or by groups of teachers, but has also provided researchers with an environment where basic research can involve long-term teaching experiments and a stable collaboration with school teachers. The two speakers gave examples where collaborations between mathematicians and school teachers responding to innovation issues have led to stable research teams from which the Italian research community has stemmed. These teams have specifically focused on whole-class interaction (beyond the more popular studies on individual problem solving and small-group cooperative learning), the teacher's role as a guide (beyond the more popular focus on learners' processes), long-term processes (beyond the more popular studies on short-term processes), and manipulation of concrete artifacts (e.g., abacuses, curve drawing devices, and tools for perspective drawing) without overlooking the theoretical aspects of mathematical processes.

The specificity of the Italian case was also highlighted in comparison with the reality of other countries. The fruitfulness of this comparison was presented by Nadia Douek and Bettina Pedemonte, who developed their PhD dissertations under the co-direction of both an Italian and a French supervisor. They reported and commented on specific collaboration experiences between French and Italian research communities and thus presented a living experience of researchers integrating different perspectives and different methodologies in a challenging but also rewarding way. Special attention was devoted to a collaborative initiative that 
involves French and Italian researchers: the case of the SFIDA (Séminaire Franco Italien de Didactique de l'Algèbre), which has displayed a rich variety of epistemological and didactic perspectives in its long life.

A final contribution, coming from East Asia, put the Italian tradition under the lens of a completely new eye. The presentation of Xuhua Sun, a colleague from Macau who recently came in contact with the Italian tradition in collaborating with Mariolina Bartolini Bussi on the organisation of the 23rd ICMI study, invited the audience to reflect on institutional and historical aspects of the Italian tradition. The focus on institutional aspects of Italian schooling included some reflections on the Italian cultural background in contrast with the Chinese one: class time, special education setting, teaching and learning freedom, etc. The historic perspective focused on aspects of mathematics and mathematics education of the Italian tradition that had an impact on the Chinese system, including some reflections on the comparison between Italian and Chinese attitudes towards proof.

\section{The Case of the Netherlands}

In accordance with Freudenthal's idea of giving reality a central role in mathematics education, the presentation on the Dutch didactic tradition started with a short movie about mathematics in the Netherlands, showing both the richness reality offers to developing mathematical concepts and tools through the process of mathematisation and the many opportunities for applying mathematics to solve real-world problems. In a second movie addressing mathematics education in the Netherlands, some snapshots from past and current classroom situations were presented. In a video interview made by Marc van Zanten, Adri Treffers then reflected on the important sources of inspiration for his ideas on mathematics education, underlining some crucial characteristics of Realistic Mathematics Education (see Sections "The Role of Theory" and "The Role of Design Activities for Teaching and Learning Environments"), in which his focus was on intra-mathematical contexts. First, he mentioned the relevance of own productions, which let students explore relations between numbers and properties of operations along with practicing their knowledge of number facts and basic skills. Second, he emphasised the significance of presenting students problems that they have not studied previously and giving them room to start with informal context-based solutions. Third, he emphasised the need to challenge students with mathematical puzzles in order to trigger students' mathematical thinking. Next, in a video interview made by Michiel Doorman, Jan de Lange told us how surprised he was when he became a teacher and discovered that students did not recognise mathematics in the world around them. He chose an extra-mathematical context and used his hobby, airplanes, to work with his students on glide ratios, vectors, and sine and cosine, all in the same context, and found that this approach even worked with low achievers. His view is that very young children should also be mathematically challenged by asking them good questions. Even simple toys can be a rich context 
for learning mathematical concepts. Education should make use of children's curiosity.

After that, Paul Drijvers presented the non-routine "driving to Hamburg" problem about making a graph. This problem requires modelling and allows solutions at different levels. Asking the audience to solve this problem by themselves let them experience what RME can mean in practice. Next, Marja van den Heuvel-Panhuizen synthesised some key aspects of RME that were touched on in the first part of the Dutch presentation and followed this by handing out two booklets in which 30 authors from the Netherlands (see http://dspace.library.uu.nl/ handle/1874/340527) and 45 authors from 16 other countries (see http://dspace. library.uu.nl/handle/1874/340526) reflected on their experiences with RME.

In the second part of the Dutch presentation, four of these authors from outside of the Netherlands signified what RME brought about in their country. David Webb did this for the USA, Zulkardi and Ratu Ilma Indra Putri for Indonesia, and Sue Hough for England and the Cayman Islands. Finally, Dirk De Bock from Belgium and Cyril Julie from South Africa acted as critical friends, mentioning RME's challenges and indicating opportunities for further development.

\section{The Case of Germany}

The two hours devoted to the German tradition were used to present a narrative on the development of the didactics of mathematics in German-speaking countries during the last decades. This sketch was enriched by snippets from longer interviews with Lisa Hefendehl-Hebeker, Hans-Georg Weigand, and Erich C. Wittmann and was followed by comments made by colleagues from Norway and Sweden, Poland, and the Czech Republic (see below).

From the sixties onwards, personal reports from mathematics classrooms and document analysis for curriculum development, subject matter didactics (Stoffdidaktik) and statistical, mainly comparative studies (often done by university psychologists) were the starting point for a fresh development in didactics of mathematics. During the sixties and seventies, research into mathematics education was institutionalised by the creation of full university professorships in didactics of mathematics, a scientific society (Gesellschaft für Didaktik der Mathematik), a research journal (Journal für Mathematik-Didaktik) and a research institute (Institut für Didaktik der Mathematik at Bielefeld University). The seventies and eighties were marked by an empirical turn to everyday classrooms with more detailed empirical research, especially with qualitative, sometimes linguistic analysis of classroom processes initiated by the Bauersfeld group. Since the eighties, the rather homogeneous field diversified into a plethora of research on a variety of aspects of the teaching and learning of mathematics, including "empirical research, subject matter didactics, applications in mathematics teaching, historical and philosophical investigations, methodological aspects of mathematics education, principles of 
mathematics education, the epistemological dimension of mathematics education and proving" (Burscheid, Struve, \& Walther, 1992, 297-302).

Not including the specific and different development in the German Democratic Republic (GDR, the eastern part of Germany), the beginning of the 21 st century and the present situation can be described by three major strands in the didactics of mathematics in the German-speaking countries. The first is Stoffdidaktik, which has widened its approach by taking into account individual psychological aspects of teaching mathematics and concentrates on the design of learning environments. The second is case studies, especially classroom studies, which use mostly qualitative methods to reconstruct diverse aspects of everyday teaching and learning with the help of a variety of research methods. As an illustration, Kerstin Tiedemann presented her study, "Helping primary students to learn math-language and interaction." The third is quantitative large-scale evaluation studies (such as TIMSS and PISA) and qualitative large-scale development studies (such as the SINUS and SINUS-transfer study), which are receiving increasing attention and are partly influenced by political concerns and demands. As an example, Stefan Krauss presented a glimpse of the COACTIV study, concentrating on the impact of professional knowledge on student achievement.

During the third hour, three critical friends presented views from outside the German-speaking countries including cooperative activities with German colleagues. Barbro Grevholm (Norway and Sweden) spoke on "Doing empirical research differently: Nordic countries and Germany," Edyta Nowinska (Poland) presented "Perspectives on collaborative empirical research in Germany and in Poland," and Nada Vondrova (Czech Republic) commented on "Didaktik der Mathematik and didaktika matematiky."

In addition to this presentation in the frame of European traditions, the Thematic Afternoon also had an activity entirely devoted to German-speaking traditions in mathematics education research made up of eight sub-sections; for details see the ICME-13 website, Chapter "German-Speaking Traditions in Mathematics Education Research" in this volume and the monograph Jahnke, Hefendehl-Hebeker \& Leuders (2018).

\section{References}

Arzarello, F., \& Bartolini Bussi, M. G. (1998). Italian trends of research in mathematics education: A national case study in the international perspective. In J. Kilpatrick \& A. Sierpinska (Eds), Mathematics education as a research domain: A search for identity (pp. 243-262). Dordrecht: Kluwer.

Brousseau, G. (1997). Theory of didactical situations in mathematics. Dordrecht: Kluwer.

Burscheid, H. -J., Struve, H., \& Walther, G (1992). A survey of research. Zentralblatt für Didaktik der Mathematik, 24(7), 296-302.

Chevallard, Y., \& Sensevy, G. (2014). Anthropological approaches in mathematics education, French perspectives. In S. Lerman (Ed.), Encyclopedia of Mathematics Education (pp. 38-43). New-York: Springer. 
Freudenthal, H. (1983). Didactical phenomenology of mathematical structures. Dordrecht: Kluwer.

Jahnke, H.-N., Hefendehl-Hebeker, L., \& Leuders, T. (Eds, 2018). Traditions in German-speaking Mathematics Education Research. New York: Springer.

Kunter, M., Baumert, J., Blum, W., Klusmann, U., Krauss, S., \& Neubrand, M. (Eds, 2013). Cognitive activation in the mathematics classroom and professional competence of teachersResults from the COACTIV project. New York: Springer.

Tobies, R. (1981). Felix Klein. Leipzig: Teubner.

Van den Heuvel-Panhuizen, M., \& Drijvers, P. (2014). Realistic mathematics education. In S. Lerman (Ed.), Encyclopedia of mathematics education (pp. 521-525). Heidelberg/New York/London: Springer.

Vergnaud, G. (1991). La théorie des champs conceptuels [The theory of conceptual fields]. Recherches en Didactique des Mathématiques, 10(2-3), 133-170.

Open Access Except where otherwise noted, this chapter is licensed under a Creative Commons Attribution 4.0 International License. To view a copy of this license, visit http://creativecommons. org/licenses/by/4.0/. 